\title{
El legado del último kraanti. Obituario al líder ette Samuel Sánchez
}

\author{
The Legacy of the Last Great Kraanti. \\ Obituary for Samuel Sánchez, an Ette Leader
}

\author{
Juan Camilo Niño Vargas* \\ Universidad de los Andes, Colombia
}

\begin{abstract}
RESUMEN
Los ette del norte de Colombia se refieren a sus más notables líderes con la palabra kraanti'. Uno de los últimos detentadores de este título, Samuel Sánchez Macías, murió recientemente, dejando un enorme vacío en su comunidad. El proyecto de resistencia y revitalización llevado a cabo por este hombre a lo largo de su vida es, en buena medida, el mismo emprendido por su pueblo desde mediados del siglo XX hasta principios del XXI. Su historia de vida es la historia de resistencia y revitalización de su pueblo.
\end{abstract}

DOI: https://doi.org/10.22380/2539472X.594

Palabras claves: ette, chimila, obituario,

líder indígena, historia de vida.

\begin{abstract}
$\overline{\text { ABSTRACT }}$
The Ette of northern Colombia call their most respected leaders kraanti. One of the last holders of this honorary title, Samuel Sánchez Macias, recently passed away, leaving a great void in their community. The project of resistance and revitalization that he led throughout his life is, to a large extent, the same undertaken by the Ette people since the mid-twentieth century. His life story is the history of resistance and revitalization of his people.
\end{abstract}

Keywords: Ette, Chimila, obituary, indigenous leader, life story.

Doctor en Antropología Social y Etnología de la École des Hautes Études en Sciences Sociales (EHESS) y magíster en Antropología de la Universidad de los Andes. Actualmente se desempeña como profesor en el Departamento de Antropología de la Universidad de los Andes. Entre sus publicaciones más recientes se encuentran Diccionario de la lengua ette (Universidad de los Andes, Instituto Colombiano de Antropología e Historia, 2018) e Indios y viajeros. Los viajes de Joseph de Brettes y Georges Sogler por el norte de Colombia (Pontificia Universidad Javeriana, Universidad de los Andes, Instituto Colombiano de Antropología e Historia, 2017). juancamilonino@gmail.com. 


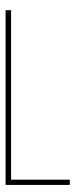

os ette del norte de Colombia aseguran residir en el centro del universo. Las llanuras que les son familiares están en el medio de mundos celestes y telúricos ocupados por otras humanidades. La tarea de mantener en equilibrio el conjunto cósmico, impedir que el cielo se desplome sobre la tierra y evitar que el suelo se hunda en las profundidades les corresponde a los ancianos detentadores del título kraanti. Si bien tal término comúnmente es traducido por los ette como “cacique”, su etimología delata significados mucho más profundos. Por un lado, remite a nociones humanas como sabiduría y ancestralidad; por otro, evoca conceptos cosmológicos como árbol primordial y columna universal.

Uno de esos soportes del universo, uno de los más altos y fuertes, desapareció en octubre del 2017. El gran kraanti Samuel Sánchez Macías, a quien muchos llamaban cariñosamente "Casimiro”, fue hallado sin vida en su hamaca. Su inesperado fallecimiento despedazó a la comunidad entera y sumió en una profunda tristeza a todos aquellos que tuvimos el honor de aprender de sus saberes. A manera de reconocimiento, creo conveniente dar a conocer su vida y su obra mediante este obituario. El legado de personas como el kraanti Samuel no solo les corresponde a los ette, sino también a todos los pueblos indígenas del continente.

Nada mejor que comenzar con un recuento de vida en primera persona. El testimonio que cito a continuación me fue transmitido por Samuel un año antes de su muerte. Hice la transcripción y traducción de sus palabras con rigurosidad, no obstante, fue necesario modificar el texto para que fuera comprensible para las personas no familiarizadas con la historia y las costumbres de los ette ${ }^{1}$.

¿De dónde provengo?

Provengo de estas tierras, tierras indígenas

De las tierras que delimitó el Gran Padre para que allí viviéramos

Nosotros los ette

Nací en una finca de propiedad de los blancos

Me convertí en un hombre pasando de una finca a otra finca

Siendo un niño trabajé en las fincas

Siendo un hombre trabajé en las fincas

Siendo un padre trabajé y trabajé

"No hables tu lengua”, decían los blancos

“¿Acaso estás hablando mal de nosotros?”, decían

El testimonio del kraanti Samuel Sánchez que se presenta fue recogido en forma oral y en lengua nativa el 11 de marzo del 2016, con el fin de completar los requerimientos para la postulación al premio que el Ministerio de Cultura le otorgó a finales del mismo año. 
“¡No hagan esos ruidos!”, nos decían invadidos por la rabia

"Mejor vete de acá, ya no tienes que hacer nada por esta tierra”

"iVete indio, busca otra tierra!”

Sus padres les habían enseñado a sentir rabia

Yo seguía hablando mi lengua y pensando en ella

Conocía la lengua de los blancos pero también conocía mi lengua

"Es mi lengua, es mi pensamiento”, me decía a mí mismo

"Es la lengua de mis abuelos, la que ellos hablaban”, me decía

Por eso pensaba en mi lengua cuando trabajaba y recorría los caminos

Nosotros teníamos que hablar en silencio

$\mathrm{Ni}$ en las fincas ni en los pueblos podíamos decir palabra

Teníamos que hablar adentro de la casa y en los huertos

Mi lengua la hablaba con mi madre y mis abuelos

La hablaba de noche para rezar y llamar al Gran Padre Yaau

A él, a Yaau, solo puede hablársele en lengua

De finca en finca terminamos viviendo en un camino

Era un camino amplio que separaba dos fincas

Muchos ette terminaron viviendo allí

Levantaron un caserío y lo bautizaron El pueblito

A los blancos no les gustaba, pero nadie quería marcharse

En el pueblito vivían grandes sabios

Yo los ayudaba en lo que podía y ellos me invitaban a rezar

Con ellos aprendí a hablar con el Gran Padre

Pero no todos eran así

Muchos compañeros querían volverse blancos

A muchos compañeros les fastidiaba ser indios

Cuando me convertí en hombre, me casé

Y con mi mujer fui a vivir a la hacienda La Sirena

En esas tierras tuve a mi primer hijo

Allí había otro pueblito de indios con muchas casitas

Vivían señores sabios, señoras sabias

Con ellos seguí aprendiendo sobre nuestro pensamiento

Todos trabajaban para un solo dueño

Y ese dueño había prometido dejarnos un pedazo de tierra

Los indios empezaron a organizarse y hablar de tener tierra propia

Algunos blancos no nos querían ver

Pero nosotros ya estábamos organizados 
Gente del Gobierno vino a visitarnos

Las hermanas lauritas y funcionarios de Santa Marta y Bogotá Al principio nos dio miedo pero vimos que era gente buena Todos nos ayudaron un poquito

Y un pedazo de la finca quedó para nosotros

“QQue vamos a hacer ahora?”, decíamos

“¿Cómo vamos a vivir en esta tierra?”, preguntábamos

A la nueva tierra la llamamos Isa Ori Tunna, "vuelve a retoñar" Ahí volveríamos a nacer y nuestro pensamiento podría retoñar El Gran Padre nos cobijaría bajo su sombra

Todos estábamos dispuestos a retoñar

¿Quién nos va a mandar ahora?

¿Quién nos va a mostrar el camino?

Los ancianos eran quienes debían mostrarnos por dónde ir

Los grandes sabios, las grandes sabias

Ese día nació el Peenarikwi, "El Consejo de Ancianos"

Y creamos el resguardo y el cabildo

En un principio, fui nombrado capitán

Los ancianos hablaban conmigo y yo con ellos

Yo llevaba su pensamiento a los jóvenes y a los blancos

Y fue así que también me convertí en un anciano

De la mano de los sabios, oyendo sus consejos

En aquella época había que hacer muchas cosas

Había que trazar un plan de vida

¿Cómo viviríamos? ¿Cómo conseguiríamos más tierras?

¿Cómo trabajaríamos? ¿Cómo le daríamos de comer a los niños?

¿Cómo seguiríamos siendo indios?

¿Cómo continuaríamos bajo la sombra del Gran Padre?

Me interesé en hacer que los jóvenes volvieran a pensar

Me interesé en hacer que los jóvenes volvieran a hablar la lengua ¿Cómo seguir pensando y hablando como ette?

Fue ese trabajo el que me propuse llevar

Ese sería mi trabajo como autoridad, como sabio, como kraanti

Primero, debíamos familiarizarnos con el colegio

Allí los niños iban a aprender la lengua y los saberes de los blancos

Era muy bueno pues necesitamos saber esas cosas

La escritura no la conozco pero sé que es importante

Nosotros necesitábamos un colegio propio 
No podíamos convertirnos en blancos

Podemos tener dos lenguas pero solo un pensamiento

El buen pensamiento, el pensamiento indio, el pensamiento del Padre

¿Que podíamos hacer?

Había que trabajar con el cabildo, el Gobierno y los funcionarios

Había que fundar colegios y formarnos como profesores

Teníamos que rescatar los conocimientos de los ancianos

Teníamos que escribir nuestra lengua y sacar libros

Había que sacar adelante la educación

Pero sobre todo había que hablar con el Gran Padre

Hacer ceremonias con toda la comunidad y pedirle protección

Para que rescatáramos nuestras palabras

Para alejar la vergüenza a la hora de hablar

Para abrir los corazones de los jóvenes

Para que las lenguas de los niños fueran ágiles

Para que todos oyeran de nuevo a los ancianos

Había que trabajar y trabajar

Además de mi cultivo y mi familia, ahora debía ir al colegio

Tenía que trabajar con los niños

Porque en ellos nuestro pensamiento renacería

A veces me pagaban, otras veces lo hacía por puro amor

Y recorriendo este camino recorrí otros caminos

Conocí mejor nuestra lengua

Fui a todos los resguardos para conocer a la comunidad

Recorrimos todos los asentamientos enseñando la escritura de la lengua

Nuestros pensamientos quedaron en varios libros para el colegio

Trabajamos en los resguardos, en pueblos y ciudades

Trabajamos con indios, blancos, colombianos y extranjeros

Así hemos alcanzado mucho

Él, el Gran Padre, ha sabido guiar nuestro pensamiento

Nos hemos dado cuenta de que nuestros conocimientos eran muchos

Nuestra lengua sigue completa, ninguna palabra se ha perdido

Hemos comprobado cómo nuestras palabras se quedan quietas en el papel

Y sabemos que los jóvenes pueden leerlas y recordarlas

Ya podemos hablar con más libertad como indios

Pero también queda mucho por recorrer

Pues muchos quieren dejar de ser indios para convertirse en blancos

¡Y eso no puede suceder! 
Porque cuando dejemos de rezarle a nuestro Gran Padre Porque cuando dejemos de pensar y hablar nuestra lengua Ese día se acabará el mundo

Yo avanzaré por el camino un poco más

Seguiré haciendo ceremonia y trabajando con los ancianos

Seguiré enseñando con los profesores

Continuaré hasta donde el Gran Padre me lo permita

Y los jóvenes seguirán el camino despejado

¡Eso es todo!

El testimonio citado debe ser situado en el mundo y el tiempo que le son propios. La vida del kraanti Samuel se desenvolvió en el seno del pueblo ette, un pequeño grupo indígena, también conocido como “chimila”, hablante de una lengua de estirpe chibcha. Los eventos que presenció y los actos que protagonizó tuvieron lugar en las llanuras del norte de Colombia, en las planicies que surca el río Ariguaní a la altura de la población de San Ángel, al suroccidente de la Sierra Nevada de Santa Marta².

Los ette lograron conservar su independencia hasta bien entrado el periodo republicano. Sin embargo, la llegada de empresas petroleras a las selvas del Ariguaní, el avance de la frontera de colonización agrícola y la instauración de un régimen latifundista de orientación ganadera pusieron fin a su relativo estado de aislamiento a mediados del siglo XX. Los indígenas perdieron el control de sus tierras, fueron obligados a desempeñarse como peones en las haciendas y empezaron a formar parte de un campesinado desposeído. La dramática situación los llevó a negar su identidad étnica y confinar al secreto su lengua y sus costumbres. No es de extrañar que muchos académicos y funcionarios creyeran que los ette eran un pueblo inexorablemente condenado a desaparecer.

Las precarias condiciones de vida de los ette empezaron a mejorar a mediados de 1980. Un clima social y político más favorable para las minorías étnicas les permitió a las nuevas generaciones impulsar un proceso de reorganización social y recuperación de tierras. La estrategia más importante que pusieron en marcha fue la creación de un resguardo y la conformación de un cabildo reconocidos por el Estado colombiano. Sus aspiraciones se concretaron a principios de 1990 con la adquisición de dos grandes terrenos cerca de Sabanas de San Ángel: Issa Oristunna y Ette Butteriya. Unos años después, a estas se sumaron otras

Sobre la historia y la cultura ette pueden consultarse las obras de Gustaf Bolinder (1924), Joseph de Brettes (1898), Gerardo Reichel-Dolmatoff (1946), Carlos Alberto Uribe Tobón (1987) y Juan Camilo Niño Vargas (2007, 2018). 
dos pequeñas propiedades en las faldas de la Sierra Nevada: Narakajmanta e Itti Takke (figura 1).

Figura 1. Territorio ette en el Caribe

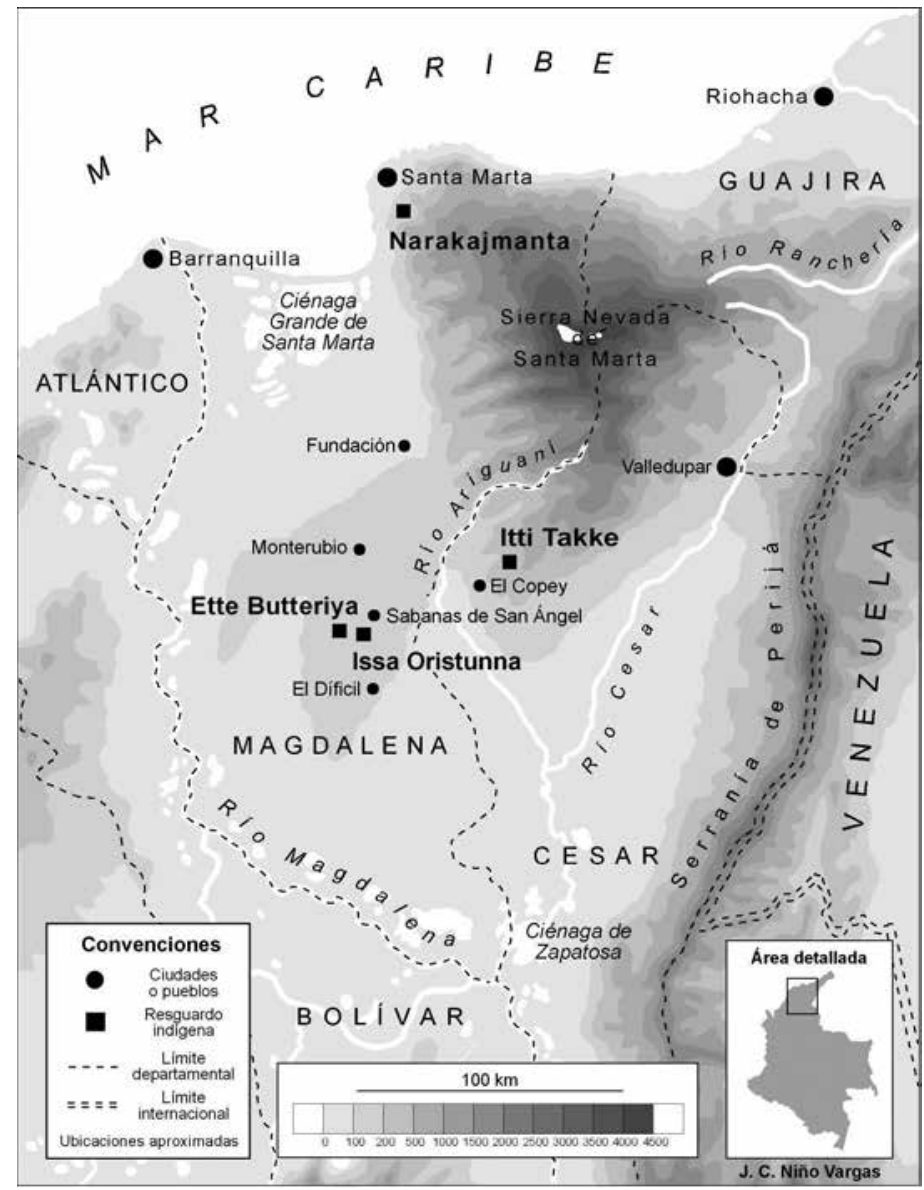

Fuente: elaboración propia.

A pesar de los éxitos logrados, el futuro de los ette sigue marcado por la incertitud. Las heridas sufridas durante décadas de opresión y marginalización no han cicatrizado por completo. Los pocos hablantes de la lengua envejecen sin poder transmitir satisfactoriamente sus competencias, los resguardos no dan abasto para albergar a toda la población y a muchas familias las aquejan la pobreza y las enfermedades. Ante tal panorama, las autoridades nacionales han declarado a los ette como un pueblo en alto grado de vulnerabilidad y riesgo de desaparición. 
Figura 2. El kraanti Samuel pasea por uno de los arroyos que cruzan los resguardos

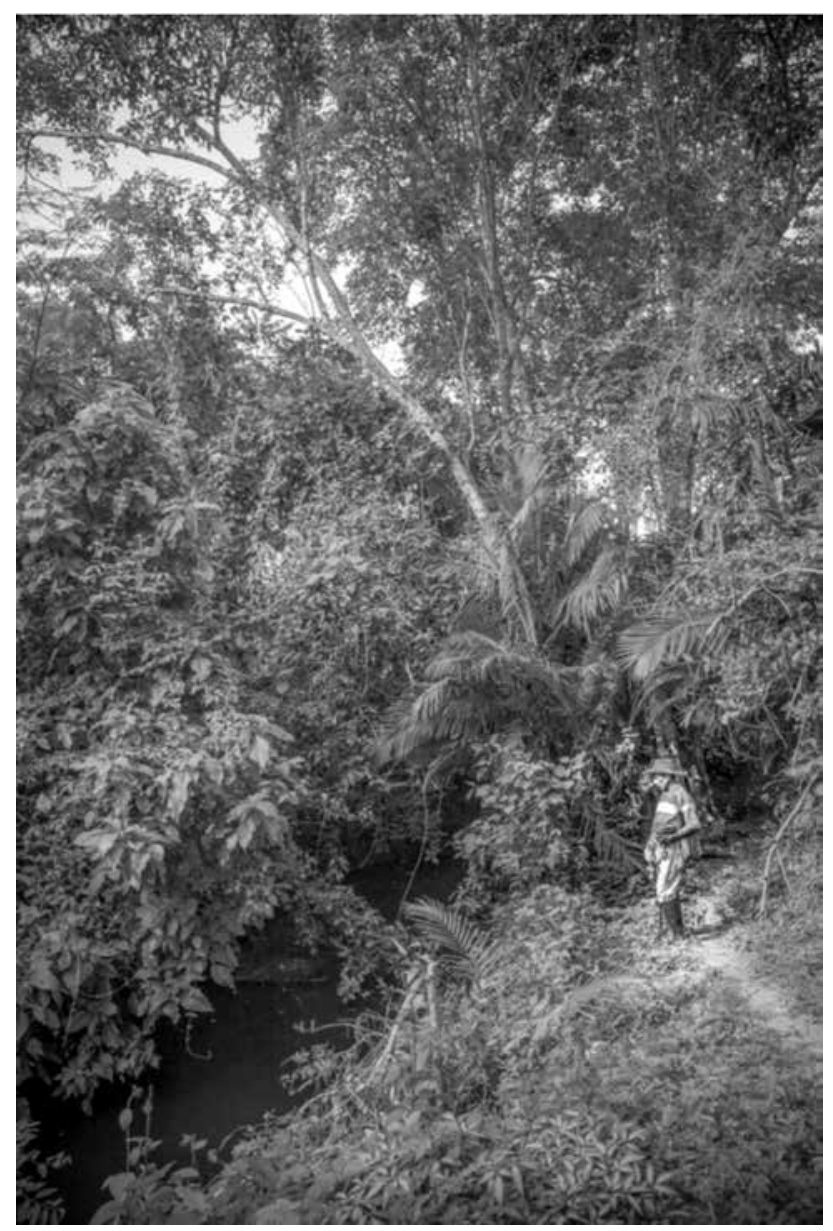

Fuente: fotografía de Juan Camilo Niño Vargas, Issa Oristunna, Magdalena, 2011.

El derrotero seguido por el kraanti Samuel ilustra la epopeya del pueblo ette $^{3}$. Nació en una humilde familia sometida al terraje en la década del cincuenta, en una de las tantas haciendas ganaderas que cubrían las llanuras. Se desconoce la fecha exacta pues por aquel entonces el calendario romano tenía mínima importancia. A diferencia de sus padres y sus abuelos, su niñez y adolescencia no transcurrieron entre selvas y cultivos, sino en medio de fincas y potreros ajenos.

3 El recuento biográfico que sigue a continuación se apoya, principalmente, en las innumerables conversaciones que sostuve con el kraanti Samuel en los resguardos de Issa Oristunna y Ette Butteriya entre el 2007 y el 2017. Al final del presente texto se ofrece una lista de documentos relacionados con la vida y la obra de este personaje, susceptibles de ser utilizados en el futuro para profundizar en su trayectoria biográfica y reconstruir el derrotero seguido por el pueblo ette desde mediados del siglo XX hasta el día de hoy. 
Como cualquier otro joven indígena, debió enfrentar la discriminación, trabajar de sol a sol y sortear los desalojos forzados. Las cosas no habrían podido ser diferentes, dado que el latifundio ya había extendido sus tentáculos sobre la región.

En un medio tan desfavorable, el joven Samuel cultivó el amor por lo propio. En vez de atender a sus padres, a quienes les había sido impuesto un sentimiento de autovergüenza, tornó su mirada hacia sus abuelos a quienes aún les gustaba hablar en lengua vernácula y observar las costumbres de antaño. Al mismo tiempo que se familiarizaba con el español y con la cultura colona en las haciendas, perfeccionaba su propio idioma en casa, realizaba largas excursiones por la selva en compañía de los adultos y aprendía los mitos de boca de los ancianos.

Un evento decisivo en la vida del kraanti Samuel tuvo lugar en la década de los ochenta. Un grupo de familias expulsadas de las haciendas, entre las cuales estaba la suya, acordó fundar un pequeño caserío a la orilla de un camino. Los ancianos presentes notaron las competencias lingüísticas y culturales del joven Samuel y no solo lo invitaron a acompañarlos en las actividades rituales sino que lo exhortaron a luchar por el pensamiento de su pueblo. La tarea era de la más alta importancia pues su objetivo último consistía en garantizar la conservación del equilibrio universal. Si los ette llegaran a desaparecer y dejaran de hablar con los dioses - como lo aseguraban los mayores-, no habría nadie que impidiera el desplome del cielo, el hundimiento de la tierra y el exterminio de la humanidad.

Con los consejos recibidos resonando en su cabeza, Samuel se trasladó con su esposa a la hacienda La Sirena, una inmensa propiedad situada en las cercanías de San Ángel. No había mejor lugar que ese para empezar a desarrollar la misión encomendada, pues allí se concentraba un centenar de indígenas de espíritu independentista. Recientemente, los líderes de la comunidad habían logrado concesiones de peso por parte del propietario del latifundio: a cambio de mano de obra barata y permanente, les concedió un permiso de residencia indefinido y, aún más importante, les prometió el derecho de propiedad de la tierra una vez él muriera. El pacto fue defendido por los indígenas frente a los reclamos de la familia del hacendado y los celos de los vecinos colonos. Varios jóvenes con mayor conocimiento de la sociedad colombiana se desplazaron a las poblaciones vecinas y llevaron la noticia del acuerdo a diversas agencias gubernamentales.

A principios de 1990, la presencia de una población indígena importante en las llanuras del Ariguaní era un hecho confirmado tanto para el Gobierno como para la academia. El apoyo externo conseguido por los ette impulsó las negociaciones informales adelantadas y facilitó la creación de un resguardo. El sector de la hacienda La Sirena ocupado por los indígenas fue puesto a título de la comunidad y rebautizado con un nombre vernáculo: Issa Oristunna, "vuelve 
a retoñar”. Unos años después, una segunda propiedad fue adquirida en la hacienda La Alemania, denominada desde entonces Ette Butteriya, "pensamiento indígena”. Junto con otros hombres y mujeres, el kraanti Samuel participó activamente en la constitución de un cabildo encargado del buen manejo de las tierras recuperadas.

Figura 3 (izquierda). El kraanti Samuel alegra una reunión comunal tocando la flauta

Figura 4 (derecha). Una lección de lengua y cultura dirigida por el kraanti Samuel en un improvisado colegio en Ette Butteriya
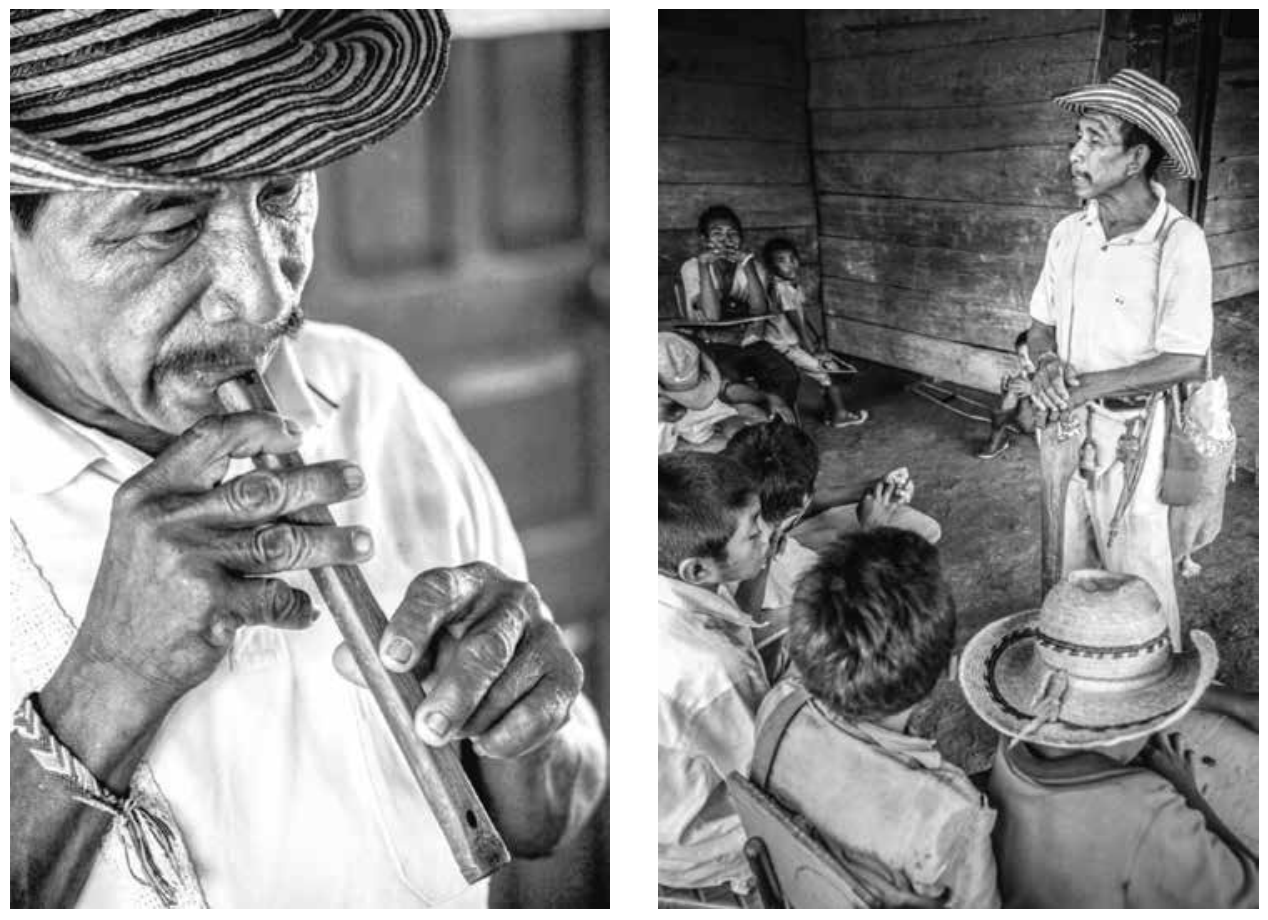

Fuente: fotografías de Juan Camilo Niño Vargas, Ette Butteriya, Magdalena, 2010 y 2011.

El liderazgo demostrado y los saberes acumulados le valieron a Samuel ser designado autoridad tradicional alrededor del año 2000. Quienes lo conocían además empezaron a anteponer a su nombre el título honorífico kraanti, reservado a los más respetados ancianos de la comunidad. Los honores recibidos le confirmaron su vocación y lo impulsaron a revitalizar el pensamiento y la lengua de su pueblo mediante dos estrategias. La primera, de carácter tradicionalista, consistía en sacar del olvido las ceremonias para comunicarse con las divinidades, de modo que fuera el mismísimo Gran Padre Yaau quien se encargara de guiar a las nuevas generaciones. La segunda, de espíritu moderno, se centraba 
en la implementación de un proyecto educativo propio, paralelo al que lideraban las hermanas lauritas en el colegio gubernamental del resguardo. Ambas iniciativas fueron retomadas en el Plan de Vida Ette Ennaka, patrocinado por la Comisión Regional de Asuntos Indígenas.

De las palabras a los hechos no debería mediar más de un paso. Apenas el cabildo y los ancianos les dieron el visto bueno a sus ideas, el kraanti concentró sus esfuerzos en rezarles a las deidades antes y después de las reuniones celebradas para tratar los asuntos comunales. Aunque de pequeño nunca asistió a la escuela, propuso la primera cátedra de lengua en el colegio dirigido por las misioneras lauritas. El carácter pionero de los proyectos supuso sortear un sinnúmero de dificultades, pero el balance final fue tan satisfactorio como esperanzador.

A partir del 2005 se inició un dinámico periodo de la vida de Samuel Sánchez. En calidad de autoridad tradicional y profesor del colegio, supervisó la planeación del Modelo Educativo Ette Ennaka, patrocinado por el Ministerio de Educación y la Universidad del Atlántico en el 2006. Pasado un año, esta universidad le otorgó un diploma honorífico que respaldaba su labor como etnoeducador. Luego asesoró el Proyecto Etnoeducativo del Pueblo Ette Ennaka, financiado por el Gobierno de Japón en el 2009, y el Autodiagnóstico Sociolingüístico de Lengua Ette Taara, realizado por el Ministerio de Cultura, la Universidad Externado de Colombia y el Gobierno Vasco en el 2010. A todas estas importantes tareas hay que agregar su apoyo incondicional al Plan de Salvaguarda impulsado por el Ministerio del Interior en el 2012 para remediar la situación de las minorías étnicas vulneradas.

Los esfuerzos de Samuel no se limitaron a la colaboración en los proyectos comunales de gran envergadura. Por el contrario, valiéndose del apoyo de algunos jóvenes, compuso y distribuyó el primer cancionero ette, Ette Kitta', de gran utilidad para la enseñanza de la lengua en la escuela. Junto con una docena de ancianos y varios profesores, coordinó una hermosa compilación de historias tradicionales que luego publicaría el Consejo Noruego para Refugiados bajo el título Nara Ette Taara Eekera'ye. Consciente del gran papel que podía desempeñar la escritura en la conservación del idioma, viajó por los resguardos junto a un joven profesor, con el propósito de dar a conocer entre sus compañeros un alfabeto práctico ette desarrollado por lingüistas profesionales. Complementó todas estas tareas con la realización de ceremonias orientadas a fortalecer el pensamiento propio y recordarles a las divinidades la obligación de velar por sus hijos.

Ya anciano, Samuel estaba convencido del papel protagónico que los ette debían asumir para dirigir su destino, así como de la necesidad de trabajar con personas ajenas para lograr tal propósito. Partiendo de esta reflexión, durante 
sus últimos años se enfiló en proyectos interétnicos dirigidos a revitalizar la lengua y visibilizar su cultura a escala local, regional y nacional. El kraanti representó a la comunidad en congresos y seminarios convocados por el Banco de la República y la Organización Nacional Indígena de Colombia. Las charlas que dio en la Biblioteca Luis Ángel Arango fueron muy ovacionadas y pusieron a los ette en los temas de conversación de indígenas y no indígenas. Sus habilidades con el arco y la flecha le merecieron una medalla en los Juegos Indígenas del Caribe. Haciendo gala de sus dotes como artesano, elaboró una serie de objetos ceremoniales para la colección permanente del Museo del Oro de Santa Marta. Haciendo gala de su generosidad, auxilió a decenas de investigadores y periodistas interesados en elaborar tesis, artículos y documentales sobre su pueblo.

Figura 5. Arco y flechas a la mano, el kraanti Samuel vigila el fuego que inaugura el ciclo de vida de los cultivos

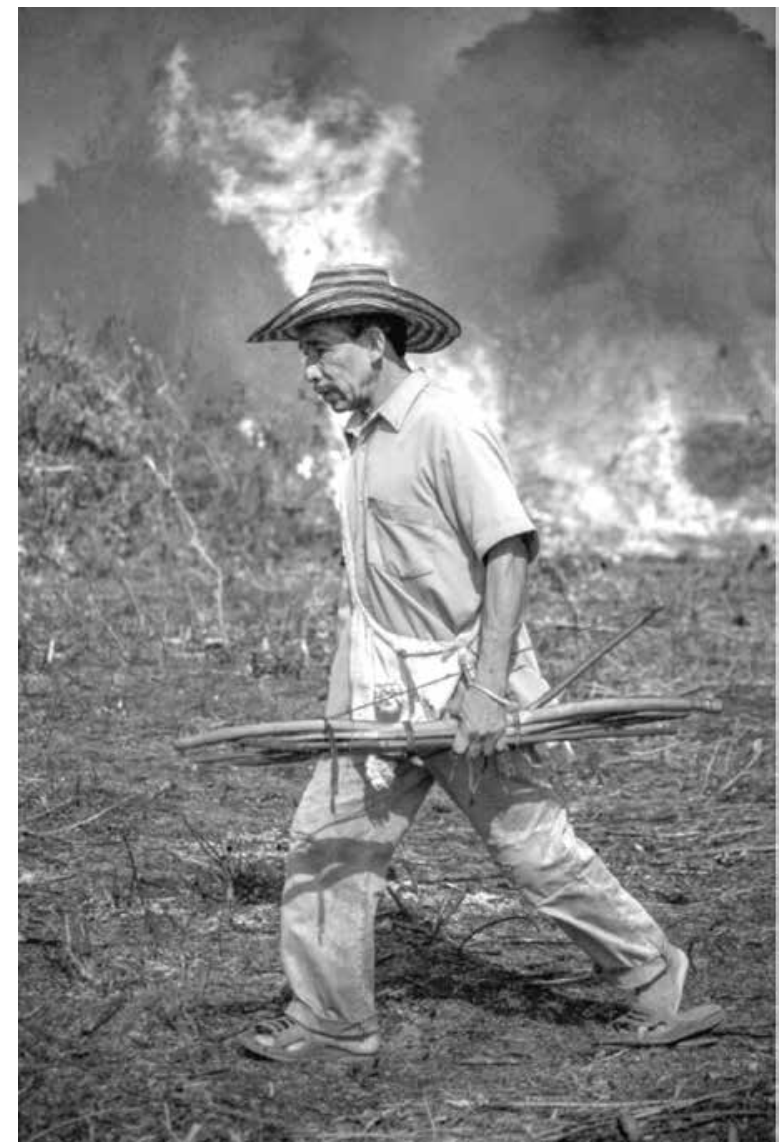

Fuente: fotografía de Juan Camilo Niño Vargas, Ette Butteriya, Magdalena, 2011. 
La valerosa empresa que lideró el kraanti Samuel por décadas le significó, al final de sus días, una de las más altas distinciones que un indígena puede recibir en el país. A finales del 2016 el Ministerio de Cultura le otorgó el Premio al Enriquecimiento de la Cultura Ancestral de los Pueblos Indígenas de Colombia. La decisión de los jueces no debió de ser muy complicada, dado que las virtudes para recibir el galardón le sobraban. Siendo un niño y un adolescente cultivó el amor por lo propio ignorando las discriminaciones de las que era objeto. $\mathrm{Al}$ alcanzar la edad adulta luchó por mejorar las condiciones de vida de su pueblo mediante la creación de un resguardo. En su vejez se entregó de tiempo completo a la vigorización ritual y práctica del pensamiento y la cultura.

La huella del kraanti Samuel es enorme. El mundo que les dejó a sus descendientes es, indudablemente, mucho mejor que aquel en el que creció. A mediados del siglo XX, los ette parecían estar abocados a la desaparición. Despojados de sus tierras, discriminados por una sociedad extraña, debían abandonar o reprimir las costumbres que pusieran en evidencia su identidad. En abierto contraste, la mayor parte de la población hoy reside en un resguardo, en donde la lengua goza de oficialidad y las normas tradicionales son legítimas. Los niños cuentan con un colegio propio, los jóvenes participan en proyectos dirigidos a rescatar las tradiciones y los ancianos detentan el título de autoridades y maestros.

De ahí la profunda pena que causa la muerte del gran Samuel. Su partida priva a una familia de un padre ejemplar, a la escuela de un maestro brillante y al pueblo ette de uno de sus más destacados líderes. Quienes tuvimos el gusto y privilegio de observarlo y escucharlo anhelamos que sus enseñanzas iluminen el camino de las futuras generaciones. El más sentido adiós al último de los grandes kraanti.

\section{Referencias}

Bolinder, Gustaf. 1924. “Die letzten Chimila-Indianer”. YMER. Svenka Sällskapet för Antropologi och geografi 44 (2): 200-228.

Brettes, Joseph de. 1898. "Chez les indiens du nord de la Colombie. Six ans d'explorations”. Le Tour du Monde 1: 61-96; 2: 434-480.

Niño Vargas, Juan Camilo. 2007. Ooyoriyasa. Cosmología e interpretación onírica entre los ette del norte de Colombia. Bogotá: Ediciones Uniandes.

—. 2018. Diccionario de la lengua ette. Bogotá: Ediciones Uniandes; Instituto Colombiano de Antropología e Historia. 
Reichel-Dolmatoff, Gerardo. 1946. “Etnografía chimila”. Boletín de Arqueología 2 (2): 95-155.

Uribe Tobón, Carlos Alberto. 1987. “Chimila”. En Introducción a la Colombia amerindia, editado por François Correa y Ximena Pachón, 51-62. Bogotá: Instituto Colombiano de Antropología.

\section{Documentos de interés relativos a la vida y la obra de Samuel Sánchez}

\section{Documentos}

Banco de la República. 2014a. Museo del Oro Tairona. Casa de la Aduana. Bogotá: Banco de la República.

—. 2014b. “Una polifonía de voces, un diálogo de saberes”. Documento oficial. Museo del Oro Tairona, Santa Marta.

Corte Constitucional, República de Colombia, 2009. Auto 004 del 2009. Documento oficial. Bogotá.

Ministerio de Cultura. 2008. Política de Protección a la Diversidad Etnoligüística. Documento oficial. Bogotá.

Ministerio del Interior. 2013. Plan de Salvaguarda Pueblo Ette Ennaka. Documento oficial. Bogotá.

Pueblo Ette Ennaka. 2000. Plan de Vida Ette Ennaka. Santa Marta: Comisión Regional de Asuntos Indígenas.

-. 2006. Modelo Educativo Ette Ennaka. Documento mecanografiado. Ministerio de Educación; Universidad del Atlántico, Barranquilla.

-.2009a. Autodiagnóstico Sociolingüístico. Lengua Ette Taara. Bogotá: Ministerio de Cultura; Universidad Externado de Colombia; Gobierno Vasco.

—.2009b. Proyecto etnoeducativo. Nata Nagkre Ori Weeke'e Ennara Butteriya Papellu Riigowala. Bogotá: Ministerio de Educación Nacional.

- 2013. Nara ette taara eekera'ye ette ennaka. Santa Marta: Consejo Noruego para Refugiados.

Sánchez Macías, Samuel. 2010. “Ette Kitta”. Documento mecanografiado. Santa Marta.

-. 2016. "Reconocimiento a la dedicación del enriquecimiento de la cultura ancestral de los pueblos indígenas de Colombia. Postulación de Samuel Sánchez Macías”. Documento mecanografíado. Bogotá. 


\section{Audiovisuales}

Ballesteros López, Judith (productora). 1996. “Issa Oristunna. La tierra de la esperanza”. Documental cinematográfico. Santa Marta: Fondo Mixto de Cultura del Magdalena.

Gallego Suárez, Juliana (productora). 2016. "Los ette. En la punta de la lengua”. Los informantes. Reportaje periodístico. Bogotá: Caracol Televisión. 